\title{
Divergência genética entre cultivares locais e cultivares melhoradas de feijão(1)
}

\author{
Lessandra Silva Rodrigues ${ }^{(2)}$, Irajá Ferreira Antunes ${ }^{(3)}$, Marcelo Grandi Teixeira ${ }^{(4)}$ e João Baptista da Silva ${ }^{(5)}$
}

Resumo - A grande variabilidade genética presente no germoplasma de feijão (Phaseolus vulgaris L.) em uso na agricultura familiar no Brasil tem sido plenamente reconhecida. A eficiência da conservação e o aproveitamento desta variabilidade aumentam quando esta é devidamente caracterizada. O objetivo deste trabalho foi caracterizar a variabilidade genética de parte do germoplasma existente em poder de produtores de feijão no Rio Grande do Sul, e de cultivares produzidas pela pesquisa, e reuni-las em grupos de similaridade genética. Foi avaliada a divergência genética de 37 cultivares locais (land races) e 14 cultivares indicadas pela pesquisa no Estado, utilizando 40 descritores morfológicos; a grande maioria desses descritores são necessários à proteção legal. Empregou-se análise multivariada, por intermédio de componentes principais e método de agrupamento. $\mathrm{O}$ uso destas técnicas possibilitou identificar descritores ineficientes ou redundantes no estudo da variabilidade genética e reunir as cultivares estudadas em quatro grupos distintos de similaridade genética. As cultivares locais revelaram variabilidade superior à encontrada nas cultivares oriundas da pesquisa, o que sugere a importância da sua inclusão em programas de melhoramento.

Termos para indexação: Phaseolus vulgaris, variedade nativa, germoplasma, variação genética.

\section{Genetic divergence in bean land races and research-developed cultivars}

\begin{abstract}
It has been recognized that the germplasm of bean (Phaseolus vulgaris L.) under use by Brazilian small-holders presents a great genetic variability. The characterization of such variability, may contribute to increase efficiency in conservation and the use of that germplasm. The aim of this work was to characterize the variability present in bean land races, to compare it with that of researchdeveloped cultivars and locate all the genotypes in similarity groups. Thirty-seven land races and 14 research-developed cultivars were evaluated by the application of 40 bean morphologic descriptors; most of them contained in the set of descriptors needed for legal protection. Principal component analysis and Ward's hierarchical method were multivariate techniques employed in the study. Inefficient or redundant descriptors were identified and four different similarity groups of cultivars were defined. Land races displayed much larger variability as compared to research-developed cultivars, suggesting the importance of their potential for bean breeding programs.
\end{abstract}

Index terms: Phaseolus vulgaris, land varieties, germplasm, genetic variation.

\footnotetext{
(1) Aceito para publicação em 9 de janeiro de 2002.

Extraído da dissertação de mestrado apresentada pelo primeiro autor à Faculdade de Agronomia Eliseu Maciel (Faem), Universidade Federal de Pelotas (Ufpel), Pelotas, RS.

(2) Ufpel, Faem, Caixa Postal 354, CEP 96001-970 Pelotas, RS. E-mail: ifant@ufpel.tche.br

(3) Embrapa-Centro de Pesquisa Agropecuária de Clima Temperado, Caixa Postal 403, CEP 96001-970 Pelotas, RS. E-mail: iraja@cpact.embrapa.br

(4) Embrapa-Centro Nacional de Pesquisa de Agrobiologia, Caixa Postal 74505, CEP 23851-970 Seropédica, RJ E-mail: grandi@cnpab.embrapa.br

(5) Ufpel. Bolsista do CNPq. E-mail: jbsilva@ufpel.tche.br
}

\section{Introdução}

A grande variabilidade genética presente no germoplasma de feijão (Phaseolus vulgaris L.) em uso na agricultura familiar no Brasil tem sido plenamente reconhecida. Esta variabilidade, existente em populações de feijão sob cultivo nas pequenas propriedades, é de fundamental importância na estratégia de sobrevivência dos pequenos agricultores, pois eles selecionam os materiais adaptados às suas condições agroecológicas e socioeconômicas, que são diferentes das encontradas nos cultivos empresariais (Cordeiro \& Marcatto, 1994). 
A variabilidade genética está sob constante pressão em direção à sua extinção, por várias causas, entre as quais, o uso de variedades uniformes, que constitui uma exigência de mercado da agricultura conceitualmente tida como moderna. Entretanto, se, de um lado, o uso de variedades altamente especializadas responde às necessidades atuais, contribuindo para o aumento da produção de alimentos, por outro, resulta em sérios prejuízos com a substituição das cultivares tradicionais (Cerezo-Mesa \& Esquinas-Alcázar, 1986).

Nos programas de melhoramento de plantas, a informação quanto à diversidade e à divergência genética dentro de uma espécie é essencial para o uso racional dos recursos genéticos (Loarce et al., 1996). Os estudos sobre a diversidade genética nas coleções de germoplasma podem ser realizados a partir de caracteres morfológicos de natureza qualitativa ou quantitativa (Moreira et al., 1994).

No estudo da divergência genética podem ser utilizados vários métodos, cuja escolha baseia-se na precisão desejada pelo pesquisador, na facilidade da análise e na forma como os dados foram obtidos. As técnicas de análise multivariada podem ser utilizadas para avaliar a divergência entre acessos e para selecionar os descritores mais importantes na discriminação dos acessos de um banco de germoplasma (Pereira et al., 1992; Amaral Júnior, 1994). Entre as técnicas estatísticas multivariadas, destacam-se a análise de componentes principais e os métodos de agrupamento (Cruz, 1990, 1997; Cruz \& Regazzi, 1997).

A análise de componentes principais consiste em transformar um conjunto original de variáveis em outro conjunto de dimensão equivalente, mas com propriedades importantes, que sejam de interesse em estudos de melhoramento. Além disso, são independentes entre si e estimados com o propósito de reter, em ordem de estimação, o máximo de informação em termos de variação total contida nos dados originais (Cruz, 1990).

Segundo Cruz \& Regazzi (1997), a viabilidade de utilização dos componentes principais em estudos de divergência genética depende da possibilidade de resumir o conjunto de variáveis originais em poucos componentes, o que significa ter uma boa aproximação do comportamento dos indivíduos, oriundo de um espaço $n$-dimensional ( $\mathrm{n}=$ número de caracteres estudados), em um espaço bi ou tridimensional.
A análise de agrupamento tem por finalidade reunir, por algum critério de classificação, os genitores em grupos, de tal forma que exista homogeneidade dentro do grupo e heterogeneidade entre grupos. Alternativamente, as técnicas de análise de agrupamento têm por objetivo, ainda, dividir um grupo original de observações em vários grupos, segundo algum critério de similaridade ou dissimilaridade (Cruz, 1990).

Os objetivos deste trabalho foram caracterizar a variabilidade genética de parte do germoplasma existente em poder dos produtores de feijão no Rio Grande do Sul, compará-la com a variabilidade genética das cultivares indicadas pela pesquisa para cultivo naquele Estado, e reunir os genótipos em grupos de similaridade genética.

\section{Material e Métodos}

Foram avaliadas 37 cultivares coletadas por técnicos da Emater-RS junto a produtores em diversas regiões produtoras de feijão do Rio Grande do Sul, sendo 28 de grãos pretos e nove de grãos de cor e 14 cultivares indicadas pela pesquisa (Tabela 1). Destas últimas, nove são de grãos pretos, e cinco, de grãos de cor. As amostras recebidas foram identificadas com um número de entrada (Tabela 2). Em sua maioria, apresentaram variabilidade fenotípica, e sempre que isto ocorreu, procedeu-se à classificação em subamostras quanto ao tamanho, forma e coloração das sementes. A amostra de trabalho predominante foi selecionada para estudo e multiplicada em casa de vegetação.

Foram instalados dois experimentos, em área pertencente à Estação Experimental Terras Baixas (EETB) da Embrapa-Centro de Pesquisa Agropecuária de Clima Temperado, Capão do Leão, RS, sendo um no campo (em janeiro de 1999), e outro, em casa de vegetação (em agosto de 1999). No experimento de campo, adotou-se o delineamento de blocos completos casualizados, com três repetições. As parcelas constituíram-se de duas fileiras de quatro metros de comprimento, distanciadas de $0,50 \mathrm{~m}$, com 12 sementes por metro linear. Durante a condução do experimento, foram efetuados os tratos culturais indicados para a cultura do feijão (Comissão Estadual de Pesquisa de Feijão, 2000).

Em casa de vegetação, foram conduzidos os testes visando determinar a reação às raças Alfa Brasil, Zeta e Capa de Colletotrichum lindemuthianum, agente causal da antracnose. Na sua determinação, foi adotado o método descrito por Rava et al. (1993).

As cultivares foram avaliadas conforme a relação de descritores estabelecida nos Descritores Mínimos do Fei- 
jão, preconizada no Decreto no 2366/97 (Brasil, 1997). Além disso, foram incluídas as variáveis cor do colo do estandarte, cor dos lóbulos do estandarte, venações nos lóbulos, cor do cálice e cor das bractéolas, segundo Irastorza (1983), reação à ferrugem, acamamento, e produtividade de grãos (produção).

As variáveis avaliadas em cada um dos diferentes estádios e pós-colheita, num total de 40, são as seguintes: em plântula: presença de antocianina nos cotilédones e no hipocótilo e dimensões da folha primária (comprimento e largura); na floração: tipo de planta, presença de antocianina no caule, cor do folíolo central, dimensões da folha, índice comprimento/largura da folha, rugosidade da folha, cor da flor (uniformidade), cor da asa da flor, cor do estandarte da flor, cor do colo do estandarte, cor dos lóbulos do estandarte, venações nos lóbulos do estandarte, cor do cálice, cor das bractéolas; na maturação fisiológica: cor da vagem (uniformidade), cor primária da vagem; na maturação de colheita: cor da vagem (uniformidade), perfil e ápice da vagem, forma e posição do dente apical da vagem e na semente: cor (uniformidade), presença de venações na testa, brilho, halo, cor do halo e grupo comercial, peso de 1.000 sementes $(\mathrm{g})$, forma $(\mathrm{J}=\mathrm{C} / \mathrm{L}$, onde $\mathrm{C}$ refere-se ao comprimento e $\mathrm{L}$, à largura da semente), grau de achatamento $(\mathrm{H}=\mathrm{E} / \mathrm{L}$, onde E refere-se à espessura $\mathrm{e} \mathrm{L}$, à largura da semente); produção, acamamento, ferrugem e reação à antracnose (raças Alfa Brasil, Zeta e Capa).

$\mathrm{Na}$ análise multivariada, relativa às variáveis componentes dos "Descritores Mínimos", os valores utilizados foram os correspondentes aos respectivos códigos de des- crição. A técnica de análise multivariada adotada foi a de componentes principais, com auxílio do programa GENES (Cruz, 1997). Os componentes principais e seus autovalores foram empregados na obtenção das estimativas das variâncias (autovalores e variação acumulada).

Os componentes principais foram estimados de modo a dispor as cultivares em um gráfico de dispersão, utilizando a dispersão dos valores das referidas cultivares, em relação aos eixos representativos dos quatro primeiros componentes principais. A identificação das variáveis que menos contribuíram para a divergência entre as cultivares foi feita de acordo com Cruz \& Regazzi (1997).

O agrupamento das cultivares foi realizado pelo método de Ward (1963), utilizando como medida de dissimilaridade a distância euclidiana ao quadrado, obtida a partir dos dados padronizados. Na formação dos grupos usaram-se os recursos computacionais do programa SPSS (Nie, 1975). O método de agrupamento permitiu traçar o dendrograma representativo dos grupos formados.

\section{Resultados e Discussão}

Na análise da divergência genética, os quatro primeiros componentes principais explicaram $69,88 \%$ da variação (Tabela 3). Nos casos em que este limite não é atingido nos dois primeiros componentes, a análise é complementada com a dispersão gráfica em relação ao terceiro e quarto componentes (Cruz \& Regazzi, 1997).

Tabela 1. Cultivares indicadas pela pesquisa para cultivo no Rio Grande do Sul no ano de 1998/99.

\begin{tabular}{|c|c|c|}
\hline Cultivar & Origem & Ano de indicação \\
\hline \multicolumn{3}{|c|}{ Grãos pretos } \\
\hline Rio Tibagi & S-89-N ${ }^{(1)}$ Introduzida do IICA/Costa Rica & 1976 \\
\hline Guateian 6662 & Introduzida do IICA/Costa Rica & 1979 \\
\hline FT 120 & (NEP 2 x ICA Pijao) x Puebla 173 & 1989 \\
\hline Macanudo & A $358 \times$ [ A $176 \times($ G $4326 \times$ XAN 40)] & 1989 \\
\hline Minuano & A $358 \times$ [ A $176 \times(G 4326 \times$ XAN 40)] & 1991 \\
\hline IAPAR 44 & (IAPAR BAC $2 \times$ RAI 12) x (RIO TIBAGI 2 x Cornell 49 242) & 1994 \\
\hline Macotaço & A $358 \times$ [ A $176 \times(\mathrm{G} 4326 \times$ XAN 40$)]$ & 1994 \\
\hline Guapo Brilhante & XAN 125 [BAT 336 (A 83 x ICA Pijao)] & 1995 \\
\hline TPS Nobre & (FT $120 \times$ FT $84-1806) \times$ FT $84-424$ & 1996 \\
\hline \multicolumn{3}{|c|}{ Grãos de cor } \\
\hline Carioca & Selecionada no IAC-Campinas, SP a partir de população local & 1976 \\
\hline Iraí & Selecionada no IPAGRO, RS a partir de população local & 1981 \\
\hline FT 206 & $-(2)$ & 1993 \\
\hline IAPAR 31 & $\begin{array}{l}\text { [(IAPAR BAC } 4 \times \text { RAI 46) x (IAPAR BAC } 2 \times \text { Iguaçu) }] \times \\
(\text { BAT } 93 \times \text { IAPAR BAC } 4)\end{array}$ & 1994 \\
\hline Tahyú( ${ }^{(3)}$ & Seleção individual realizada no IPEAS, RS a partir de população local & 1974 \\
\hline
\end{tabular}

${ }^{(1)}$ Denominação com que chegou ao Brasil. ${ }^{(2)}$ Informação não disponível. ${ }^{(3)}$ Cultivar retirada da indicação para cultivo. 
Pelo critério sugerido por Cruz \& Regazzi (1997), ma da semente (J = C/L), grupo comercial, cor primáconclui-se que as variáveis de menor importância, ria da vagem na maturação fisiológica, dimensões da no presente estudo, foram na ordem de: peso de 1.000 folha, acamamento, presença de antocianina no sementes, índice comprimento e largura da folha hipocótilo, cor da flor (uniformidade), rugosidade da $(\mathrm{ICLF}=\mathrm{C} / \mathrm{L})$, largura e comprimento da folha primá- folha, presença de venações nos lóbulos do estanria, grau de achatamento da semente $(\mathrm{H}=\mathrm{E} / \mathrm{L})$, for- darte, cor do colo do estandarte, brilho da semente,

Tabela 2. Número de acesso, nome comum, número de anos de cultivo, cor da semente e região de origem das cultivares oriundas de produtores do Rio Grande do Sul.

\begin{tabular}{|c|c|c|c|c|}
\hline $\begin{array}{l}\mathrm{N}^{\mathrm{o}} \mathrm{de} \\
\text { acesso }\end{array}$ & Nome comum & $\begin{array}{l}\text { Anos de } \\
\text { cultivo }\end{array}$ & Região de origem $^{(1)}$ & Cor da semente \\
\hline 2 & $-^{(2)}$ & 10 & Alto Uruguai & Preta \\
\hline 5 & - & 12 & Alto Uruguai & Preta \\
\hline 6 & Guabiju & 12 & Alto Uruguai & Preta \\
\hline 7 & - & 4 & Alto Uruguai & Preta \\
\hline 8 & - & 10 & Alto Uruguai & Preta \\
\hline 9 & Azulão & 12 & Alto Uruguai & Preta \\
\hline 14 & Taquara & 5 & Alto Uruguai & Preta \\
\hline 15 & - & 3 & Alto Uruguai & Preta \\
\hline 16 & - & 6 & Alto Uruguai & Preta \\
\hline 19 & - & 10 & Alto Uruguai & Preta \\
\hline 20 & - & 6 & Alto Uruguai & Preta \\
\hline 21 & - & 20 & Alto Uruguai & Preta \\
\hline 23 & - & 20 & Alto Uruguai & Preta \\
\hline 24 & - & 20 & Depressão Central & Preta \\
\hline 25 & Vagem Roxa & - & Depressão Central & Preta \\
\hline 26 & - & 8 & Alto Uruguai & Preta \\
\hline 29 & - & 18 & Alto Uruguai & Preta \\
\hline 30 & Chumbinho & - & Depressão Central & Preta \\
\hline 32 & - & - & Alto Uruguai & Vermelha escura \\
\hline 34 & - & - & Metropolitana e Litoral Norte & Preta \\
\hline 35 & Crioulo Taquara & 26 & Planalto & Preta \\
\hline 36 & Moleque & 3 & Planalto & Preta \\
\hline 37 & Paraná & 3 & Planalto & Preta \\
\hline 38 & Feijão-Moro & 20 & Planalto & Acinzentada com estrias pretas \\
\hline 39 & Azulão & 9 & Planalto & Preta \\
\hline 42 & Amendoim & - & Zona Sul & Vermelha escura (vinho) \\
\hline 43 & Pitanga & - & Depressão Central & Vermelha escura \\
\hline 44 & Feiião-Verde & - & Planalto & Verde escura \\
\hline 45 & Mourinho & - & Zona Sul & Acinzentada com estrias pretas \\
\hline 47 & $\begin{array}{l}\text { Vaquinha Holandesa } \\
\text { Branca e Preta }\end{array}$ & - & Zona Sul & Branca e preta \\
\hline 49 & $\begin{array}{l}\text { Vaquinha Holandesa } \\
\text { Branca e Vermelha }\end{array}$ & - & Planalto & Branca e vermelha \\
\hline 50 & Guabiju & - & Depressão Central & Preta \\
\hline 52 & Cinqüentinha & - & Depressão Central & Preta \\
\hline 56 & Charque & - & - & Preta \\
\hline 57 & Taquara & - & Alto Uruguai & Preta \\
\hline 61 & Vagem Roxa & - & Campanha & Preta \\
\hline 62 & Murrinha & - & Depressão Central & Acinzentada com estrias pretas \\
\hline
\end{tabular}

(1)Regiões administrativas da Emater-RS: Alto Uruguai, Planalto, Depressão Central, Serra, Metropolitana e Litoral Norte, Zona Sul, Campanha, Vale do Taquari e Noroeste. (2)Informação não disponível. 
ferrugem, forma do dente apical da vagem, cor da semente (uniformidade), ápice da vagem, reação à antracnose (raça Capa), presença de antocianina nos cotilédones, cor da vagem (uniformidade) na maturação de colheita, reação à antracnose (raça Zeta) e posição do dente apical da vagem. Estas 25 variáveis, de um total de 40, são dispensáveis ou redundantes, por apresentarem alta correlação com variáveis mais importantes. Adotando este critério, Choer \& Silva (2000) identificaram 21 caracteres redundantes na divergência genética de Cucurbita ssp.

Este fato evidencia a importância da utilização de técnicas multivariadas (componentes principais) na identificação de caracteres, que realmente devem ser avaliados com base em um estudo prévio da sua contribuição para a variabilidade (Pereira, 1989). $\mathrm{O}$ interesse nessa avaliação reside na possibilidade de se descartarem caracteres que contribuam pouco

Tabela 3. Variância de cada componente principal e sua importância em relação à variância total.

\begin{tabular}{crrc}
\hline Componente & Variância & $\begin{array}{c}\text { Variância } \\
(\%)\end{array}$ & $\begin{array}{c}\text { Variância } \\
\text { acumulada (\%) }\end{array}$ \\
\hline 1 & 14,5956 & 36,4891 & 36,4891 \\
2 & 7,1433 & 17,8584 & 54,3476 \\
3 & 4,1656 & 10,4140 & 64,7616 \\
4 & 2,0509 & 5,1272 & 69,8889 \\
\hline
\end{tabular}

para a discriminação dos genótipos avaliados, reduzindo, dessa forma, mão-de-obra, tempo e custos despendidos, na experimentação agrícola (Cruz \& Regazzi, 1997).

Na Tabela 4, após o descarte dos descritores redundantes, em relação ao primeiro componente principal, os descritores de maior contribuição na discriminação das cultivares foram produção, cor do estandarte, cor dos lóbulos do estandarte, tipo de planta e presença de venações na testa (tegumento) da semente; no segundo componente, destacaram-se uniformidade da vagem na maturação fisiológica, presença de antocianina no caule, cor do folíolo central, perfil da vagem e cor das asas da flor; no terceiro componente, cor do cálice e presença de halo e novamente os descritores tipo de planta, uniformidade da vagem na maturação fisiológica e presença de antocianina no caule; e no quarto componente, os descritores perfil da vagem, reação à antracnose (raça Alfa Brasil), cor do halo e cor das asas. Os coeficientes de correlação entre estes descritores e os componentes principais são altamente significativos. Isto corrobora Iezzoni \& Pritts (1991), que afirmam que, geralmente, descritores com maiores autovetores e maiores coeficientes de correlação são considerados de maior importância para o respectivo componente. Destes descritores, cor da flor e cor do halo estão incluídos em um grupo restrito, composto por

Tabela 4. Autovetor (Av), coeficiente de correlação (r) dos descritores de feijão com os componentes principais (CP) para os descritores não descartados.

\begin{tabular}{|c|c|c|c|c|c|c|c|c|}
\hline \multirow[t]{2}{*}{ Descritor } & \multicolumn{2}{|c|}{$\mathrm{CP}_{1}$} & \multicolumn{2}{|c|}{$\mathrm{CP}_{2}$} & \multicolumn{2}{|c|}{$\mathrm{CP}_{3}$} & \multicolumn{2}{|c|}{$\mathrm{CP}_{4}$} \\
\hline & Av & $\mathrm{r}$ & Av & $\mathrm{r}$ & $\mathrm{Av}$ & $\mathrm{r}$ & Av & $\mathrm{r}$ \\
\hline Tipo de planta ${ }^{(1)}$ & 0,161 & $0,6181 * *$ & 0,008 & 0,0235 & 0,322 & $0,6583 * *$ & 0,097 & 0,1394 \\
\hline Antocianina no caule ${ }^{(1)}$ & 0,082 & $0,3155^{*}$ & 0,230 & $0,6170^{* *}$ & 0,259 & $0,5298 * *$ & 0,114 & 0,1646 \\
\hline Cor de folíolo central ${ }^{(1)}$ & 0,139 & $0,5326 * *$ & $-0,166$ & $-0,4450 * *$ & 0,180 & $0,3694 * *$ & 0,100 & 0,1433 \\
\hline Cor das asas ${ }^{(1)}$ & 0,145 & $0,5564 * *$ & $-0,154$ & $-0,4121 * *$ & 0,037 & 0,0773 & 0,250 & $0,3585 * *$ \\
\hline Cor do estandarte ${ }^{(1)}$ & 0,215 & $0,8244 * *$ & 0,060 & 0,1625 & 0,005 & 0,0100 & 0,047 & 0,0682 \\
\hline Cor - lóbulos do estandarte & $-0,177$ & $-0,6776 * *$ & $-0,151$ & $-0,4040^{* *}$ & $-0,113$ & $-0,2306$ & 0,072 & 0,1042 \\
\hline Cor do cálice & $-0,092$ & $-0,3533 *$ & 0,079 & 0,2121 & 0,378 & $0,7727 * *$ & 0,074 & 0,1066 \\
\hline Cor das bractéolas & 0,038 & 0,1462 & 0,024 & 0,0649 & 0,141 & $0,2876^{*}$ & $-0,250$ & $-0,3581 * *$ \\
\hline Vagem: cor - uniformidade ${ }^{(1)}$ & $-0,032$ & $-0,1244$ & 0,226 & $0,6043^{* *}$ & 0,317 & $0,6484 * *$ & 0,065 & 0,0942 \\
\hline Perfil $^{(1)}$ & $-0,017$ & $-0,0656$ & $-0,165$ & $-0,4429 * *$ & 0,140 & $0,2870^{*}$ & $-0,435$ & $-0,6235^{* *}$ \\
\hline Venações na testa ${ }^{(1)}$ & $-0,159$ & $-0,6089 * *$ & $-0,073$ & $-0,1950$ & $-0,095$ & $-0,1949$ & $-0,055$ & $-0,0790$ \\
\hline Presença de halo ${ }^{(1)}$ & 0,006 & 0,0235 & 0,059 & 0,1588 & $-0,264$ & $-0,5396^{* *}$ & $-0,022$ & $-0,0314$ \\
\hline Cor do halo ${ }^{(1)}$ & $-0,137$ & $-0,5266 * *$ & $-0,069$ & $-0,1858$ & $-0,046$ & $-0,0950$ & 0,356 & $0,5104 * *$ \\
\hline Produção & 0,224 & $0,8570 * *$ & $-0,126$ & $-0,3375^{*}$ & 0,044 & 0,0905 & 0,005 & 0,0077 \\
\hline Alfa Brasil & $-0,015$ & $-0,0595$ & 0,121 & $0,3259^{*}$ & 0,108 & 0,2213 & 0,374 & $0,5367 * *$ \\
\hline
\end{tabular}

${ }^{(1)}$ Descritor para proteção legal. * e ${ }^{*}$ Significativo a $5 \%$ e a $1 \%$ de probabilidade, respectivamente, pelo teste $\mathrm{t}$. 
mais cinco descritores, que são: a pigmentação do hipocótilo, o dente apical da vagem, a cor do tegumento e o brilho e forma da semente, utilizados para comparação entre uma cultivar apresentada para proteção, com uma outra já descrita. Estes descritores são denominados descritores fixos, por dependerem de um ou de poucos genes e por serem de fácil diferenciação fenotípica (Brasil, 1997). Segundo Ramalho et al. (1993), caracteres pouco influenciados pelo ambiente e possivelmente controlados por poucos genes, com herança qualitativa, são bons marcadores genéticos.

Os escores dos quatro primeiros componentes principais, que foram utilizados na transposição geométrica dos acessos, estão relacionados na Tabela 5 .

Com base nas características, principalmente morfológicas, avaliadas, e utilizando-se os escores obtidos na análise por componentes principais, realizou-se o agrupamento pelo método hierárquico de Ward (Figura 1), o qual permitiu classificar os acessos em quatro grupos, a saber: o grupo I $(06,07,09$, $19,05,02$ e 08$)$ e o grupo II $(14,20,15,21$ e 16), formados somente por cultivares locais; o grupo III (49, Tahyú, Carioca, IAPAR 31, 42, FT 206, 32, 43, 47, 44 e Iraí), constituído por cultivares de grãos de cor, tanto locais quanto melhoradas, e o grupo IV $(29,61$, FT 120, 34, IAPAR 44, Rio Tibagi, 24, Guapo Brilhante, 56, TPS Nobre, 30, Macanudo, Minuano, 57, Macotaço, 25, 26, Guateian 6662, 23, 36, 37, 45, 50, 35, $52,39,38$ e 62 ), formado por todas as cultivares de grãos pretos indicadas pela pesquisa, além de cultivares locais de grãos pretos e de tipo mouro $(38,45$ e 62).

Por esta análise pode verificar-se que cultivares locais apresentando nomes iguais fazem parte de grupos diferentes. As cultivares com denominações Guabiju, de números de entrada 06 e 50, e Azulão, 09 e 39, ficaram em grupos distintos, I e IV, respectivamente, e as cultivares com denominação Taquara, 14 e 57, nos grupos II e IV. Entre as cultivares com nomes iguais, somente as cultivares Vagem Roxa, 25 e 61, foram classificadas no mesmo grupo (IV). Fonseca \& Silva $(1997,1999)$ constataram fato semelhante ao estudarem cultivares locais com as denominações de Chumbinho, Taquara e Mamoninha, em 1997, e Amendoim e Chita Fina, em 1999. Desta for- ma, evidencia-se a necessidade de caracterizar cada um dos acessos que chegam a determinado programa de conservação de germoplasma ou de melhoramento genético, visto que a simples denominação é um parâmetro não confiável.

Outra constatação foi a disposição de todas as cultivares de grãos pretos, oriundas da pesquisa, dentro de um mesmo grupo. É possível visualizar o grau de proximidade de algumas destas cultivares, como é o caso das cultivares Rio Tibagi e IAPAR 44. Esta última, provém de cruzamento em que Rio Tibagi é uma das cultivares parentais, e ambas estão inseridas no mesmo grupo, lado a lado, no dendrograma; o mesmo ocorreu com as cultivares Macanudo, Minuano e Macotaço que são originárias do mesmo cruzamento.

Esta proximidade sugere a utilização, para fins comerciais, das mesmas fontes de genes, cuja origem pode ser, até certo ponto, a influência do programa de melhoramento desenvolvido no Centro Internacional de Agricultura Tropical (CIAT), Colômbia, sobre toda a América Latina, que certamente, contribuiu para uma maior uniformização nas cultivares produzidas pelos diversos programas no País. Também, relativamente a estas cultivares, deve ser citada a origem comum de Rio Tibagi e Guateian 6662, que foram introduzidas a partir do Instituto Interamericano de Ciências Agrícolas (IICA), da Costa Rica, e chegaram à Região Sul do Brasil, através do Ministério da Agricultura, no fim da década de 60. A cultivar Rio Tibagi, em particular, tem sido muito utilizada em cruzamentos, não só no Brasil, mas também no CIAT, estando presente na genealogia de inúmeras cultivares.

Ainda, considerando as cultivares de grãos pretos, as significativas distâncias observadas entre determinados pares de cultivares oriundas da pesquisa e de produtores, ressaltam a importância destas últimas para os programas de melhoramento, pelo possível aporte de novas combinações gênicas que estas podem proporcionar àquelas. Exemplo disso é a comparação entre qualquer das cultivares oriundas da pesquisa e as constituintes do primeiro grupo, Guabiju (06), 07 e 08, todas de grãos pretos. A distância entre os dois grupos sugere que a exploração de populações híbridas derivadas do intercruzamento de seus integrantes poderá levar ao surgimento de interessantes recombinações. 
Tabela 5. Escores das cultivares de feijão (locais e melhoradas) em relação aos quatro componentes principais (CP).

\begin{tabular}{|c|c|c|c|c|c|}
\hline $\begin{array}{l}\text { Número } \\
\text { de ordem }\end{array}$ & Genótipo $^{(2)}$ & $\mathrm{CP}_{1}$ & $\mathrm{CP}_{2}$ & $\mathrm{CP}_{3}$ & $\mathrm{CP}_{4}$ \\
\hline 1 & 02 & 6,0129 & $-0,7470$ & 8,9271 & 0,9526 \\
\hline 2 & 05 & 4,5046 & 0,5626 & 8,3862 & 0,2760 \\
\hline 3 & 06/ Guabiju & 5,4317 & 0,0807 & 8,9712 & 0,1261 \\
\hline 4 & 07 & 5,4688 & 0,0401 & 8,8094 & 0,1778 \\
\hline 5 & 08 & 5,8205 & $-0,9008$ & 8,3478 & $-0,1755$ \\
\hline 6 & 09/ Azulão & 4,7754 & $-0,1320$ & 9,0545 & 0,3360 \\
\hline 7 & 14/ Taquara & 1,7223 & 10,1725 & 6,8605 & 1,5456 \\
\hline 8 & 15 & 1,9333 & 9,7223 & 5,1560 & $-1,2346$ \\
\hline 9 & 16 & 4,7388 & 8,2066 & 6,4502 & $-0,8846$ \\
\hline 10 & 19 & 5,5397 & 0,4319 & 9,4723 & 0,7623 \\
\hline 11 & 20 & 1,7659 & 9,7265 & 6,5448 & 1,5012 \\
\hline 12 & 21 & 2,0937 & 11,3533 & 5,2478 & 0,7068 \\
\hline 13 & 23 & $-3,6451$ & 4,8447 & 9,3845 & $-2,2849$ \\
\hline 14 & 24 & $-3,7969$ & 3,3771 & 9,5702 & $-0,9109$ \\
\hline 15 & 25/ Vagem Roxa & $-4,5937$ & 4,4751 & 9,7257 & $-0,5871$ \\
\hline 16 & 26 & $-4,2452$ & 4,2239 & 10,083 & $-0,9171$ \\
\hline 17 & 29 & $-4,1774$ & 3,5583 & 9,3919 & $-0,2967$ \\
\hline 18 & 30/ Chumbinho & $-3,7651$ & 3,6097 & 9,7406 & $-1,1329$ \\
\hline 19 & 32 & $-5,2578$ & 0,8010 & 4,7367 & $-0,4214$ \\
\hline 20 & 34 & $-4,6973$ & 3,4945 & 9,6344 & $-1,4964$ \\
\hline 21 & 35/ Crioulo Taquara & $-5,3771$ & 3,0976 & 10,0965 & 1,6148 \\
\hline 22 & 36/ Moleque & $-5,2525$ & 3,2985 & 9,3502 & 2,8313 \\
\hline 23 & 37/ Paraná & $-5,1163$ & 3,6681 & 8,9730 & 3,5799 \\
\hline 24 & 38/ Feijão-Moro & $-4,2293$ & 2,0733 & 8,0930 & 1,1350 \\
\hline 25 & 39/ Azulão & $-5,5880$ & 2,8248 & 9,5846 & 1,6781 \\
\hline 26 & 42/ Amendoim & $-3,7675$ & 1,4013 & 5,3734 & $-0,1145$ \\
\hline 27 & 43/ Pitanga & $-4,9748$ & 0,8426 & 4,6119 & 0,3260 \\
\hline 28 & 44/ Feijão-Verde & $-4,3998$ & 1,4080 & 4,7701 & 1,5809 \\
\hline 29 & 45/ Mourinho & $-5,2970$ & 2,5683 & 7,6373 & 3,3979 \\
\hline 30 & 47/ Vaquinha Holandesa Branca e Preta & $-5,3484$ & 1,0144 & 5,7048 & 0,2663 \\
\hline 31 & 49/ Vaquinha Holandesa Branca e Vermelha & $-5,3114$ & 1,0483 & 2,8411 & $-0,9668$ \\
\hline 32 & $50 /$ Guabiju & $-4,8579$ & 3,4974 & 7,7851 & 3,1970 \\
\hline 33 & 52/ Cinqüentinha & $-5,2368$ & 3,1593 & 9,9992 & 1,5640 \\
\hline 34 & 56/ Charque & $-3,8753$ & 3,9096 & 9,9043 & $-1,0112$ \\
\hline 35 & 57/ Taquara & $-3,7767$ & 4,4853 & 9,8360 & $-1,0568$ \\
\hline 36 & 61/ Vagem Roxa & $-4,3521$ & 3,6926 & 9,9748 & $-0,0011$ \\
\hline 37 & 62/ Murrinha & $-4,9235$ & 2,9474 & 8,1399 & 1,7415 \\
\hline 38 & Rio Tibagi & $-4,6324$ & 3,8533 & 9,6853 & $-1,1159$ \\
\hline 39 & Macotaço & $-3,8903$ & 4,6081 & 9,6244 & $-1,3522$ \\
\hline 40 & Minuano & $-4,0308$ & 3,5696 & 10,1181 & $-1,3968$ \\
\hline 41 & Macanudo & $-3,6107$ & 3,6508 & 10,0018 & $-1,0590$ \\
\hline 42 & Guateian & $-3,7655$ & 4,3191 & 9,7552 & $-0,5029$ \\
\hline 42 & FT 120 & $-4,7918$ & 4,4410 & 9,4029 & 0,5115 \\
\hline 44 & Iapar 44 & $-4,4096$ & 3,7826 & 9,4258 & $-1,6620$ \\
\hline 45 & Guapo & $-3,9119$ & 3,5704 & 9,1556 & $-0,8846$ \\
\hline 46 & TPS Nobre & $-3,7937$ & 3,9932 & 9,6944 & $-1,1794$ \\
\hline 47 & Iraí & $-4,7444$ & 2,6045 & 5,0676 & 0,7078 \\
\hline 48 & Carioca & $-4,8790$ & 1,9931 & 5,8546 & $-0,9367$ \\
\hline 49 & FT 206 & $-2,9591$ & 2,4096 & 5,6504 & $-1,0828$ \\
\hline 50 & Iapar 31 & $-4,3771$ & 1,2847 & 5,4727 & $-1,5690$ \\
\hline 51 & Tahyú & $-4,4605$ & 1,1924 & 4,1193 & $-2,2778$ \\
\hline
\end{tabular}

${ }^{(1)}$ Números de ordem de 38 a 51 indicam cultivares melhoradas. ${ }^{(2)}$ Quando da existência de denominação para cultivar local, esta segue o número do acesso no Programa de Melhoramento de Feijão da Embrapa-Centro de Pesquisa Agropecuária de Clima Temperado. 


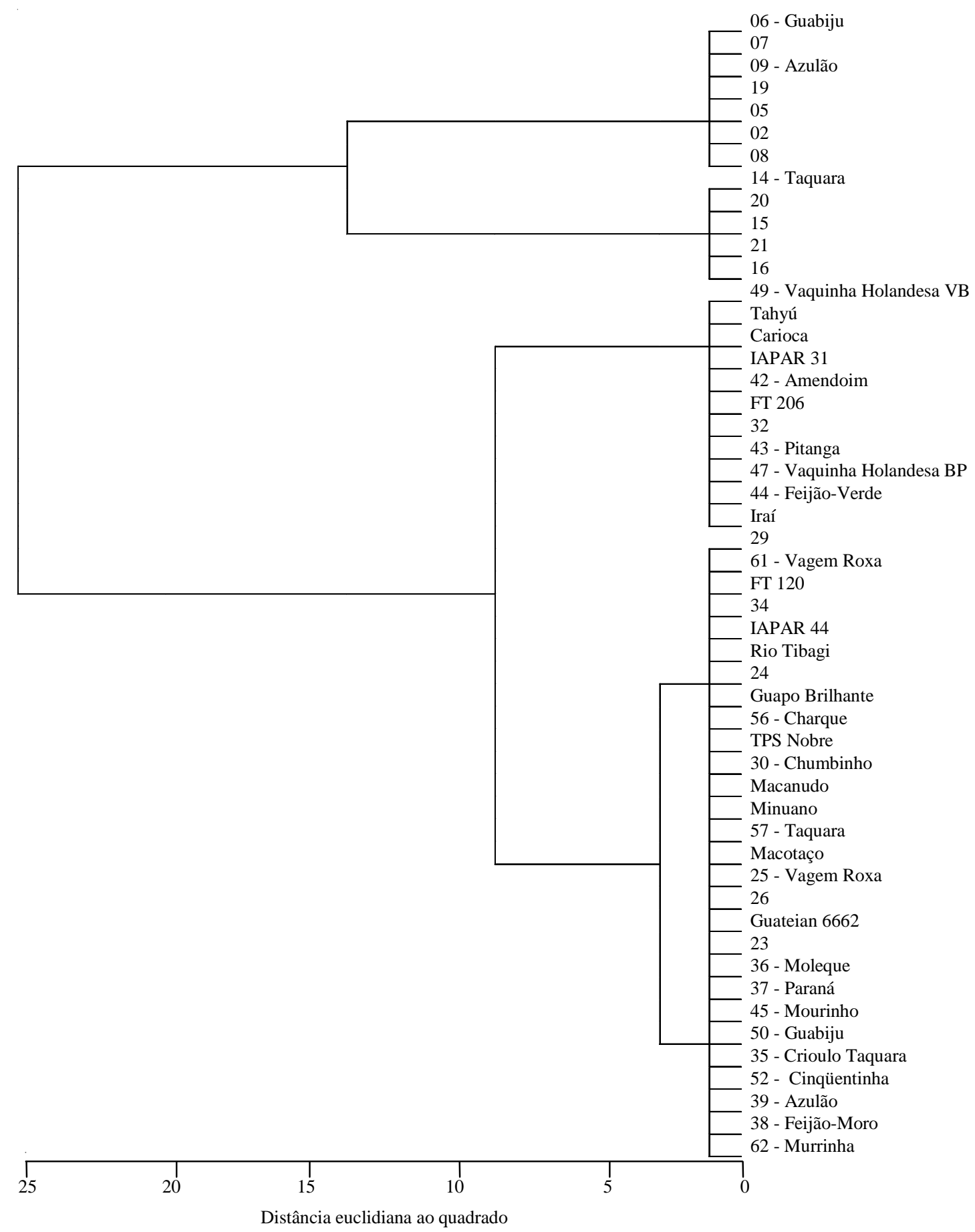

Figura 1. Dendrograma do padrão de similaridade estabelecido pela análise de agrupamento pelo método hierárquico de Ward, com base nas distâncias euclidianas ao quadrado, para as 51 cultivares de feijão. 
A proximidade entre as cultivares desenvolvidas pela pesquisa também pode ser verificada entre as de grãos de cor, Tahyú, Carioca, IAPAR 31, FT 206 e Iraí, que se encontram em um mesmo grupo. No presente estudo, há de se destacar o papel predominante assumido pela cultivar Carioca, que foi e tem sido largamente utilizada como parental no desenvolvimento de cultivares com semelhante padrão de cores do tegumento.

Entre os acessos de germoplasma avaliados, cabe destacar as cultivares Mourinho (45), Feijão-Moro (38) e Murrinha (62) como promissoras no cruzamento com cultivares de grãos de cor, derivadas da pesquisa, dada a distância que há entre elas.

\section{Conclusões}

1. Há significativa divergência entre cultivares locais de feijão, bem como entre estas e as que foram desenvolvidas pela pesquisa, potencializando, assim, o seu aproveitamento.

2. As cultivares de feijão em poder dos agricultores do Rio Grande do Sul apresentam maior variabilidade genética, quando comparadas com as geradas pela pesquisa.

\section{Referências}

AMARAL JÚNIOR, A. T. do. Análise multivariada e isoenzimática da divergência genética entre acessos de moranga (Cucurbita maxima Duchesne). 1994. 95 f. Dissertação (Mestrado) - Universidade Federal de Viçosa, Viçosa.

BRASIL. Presidência da República. Decreto oํ 2.366, de 05 de novembro de 1997. Regulamenta a Lei no 9.456, de 25 de abril de 1997, que institui a Proteção de Cultivares, dispões sobre o Serviço Nacional de Proteção de Cultivares - SNPC, e dá outras providências. Diário Oficial [da] República Federativa do Brasil, Brasília, no 216, 7 de nov. 1997. Seção 1, p. 25333-25354.

CEREZO-MESA, M.; ESQUINAS-ALCÁZAR, J. T. El germoplasma vegetal en los países del Cono Sur de América Latina. Roma: Consejo Internacional de Recursos Fitogenéticos, 1986. 183 p.

CHOER, E.; SILVA, J. B. da. Avaliação da divergência genética entre acessos de Cucurbita spp. através de análise multivariada. Agropecuária de Clima Temperado, Pelotas, v. 3, n. 2, p. 213-219, 2000.
COMISSÃO ESTADUAL DE PESQUISA DE FEIJÃO (Santa Maria, RS). Feijão: recomendações técnicas para cultivo no Rio Grande do Sul. Santa Maria: Pallotti, 2000. $80 \mathrm{p}$.

CORDEIRO, A.; MARCATTO, C. Milho: a volta das variedades crioulas. In: GAIFANI, A.; CORDEIRO, A. (Org.). Cultivando a diversidade: recursos genéticos e segurança alimentar. Rio de Janeiro: Assessoria e Serviços a Projetos em Agricultura Alternativa, 1994. 205 p.

CRUZ, C. D. Aplicação de algumas técnicas multivariadas no melhoramento de plantas. 1990. $188 \mathrm{f}$. Tese (Doutorado) - Escola Superior de Agricultura Luiz de Queiroz, Piracicaba.

CRUZ, C. D. Programa GENES: aplicativo computacional em genética e estatística. Viçosa, MG: UFV, 1997. $390 \mathrm{f}$.

CRUZ, C. D.; REGAZZI, A. J. Modelos biométricos aplicados ao melhoramento genético. Viçosa, MG: Imprensa Universitária, 1997. 390 p.

FONSECA, J. R.; SILVA, H. T. da. Emprego da análise multivariada na caracterização de acessos de feijão (Phaseolus vulgaris L.). Revista Brasileira de Sementes, Campinas, v. 19, n. 2, p. 335-341, 1997.

FONSECA, J. R.; SILVA, H. T. da. Identificação de acessos de feijão por meio de técnicas multivariadas. Pesquisa Agropecuária Brasileira, Brasília, v. 34, n. 3, p. 409-414, mar. 1999.

IEZZONI, A. F.; PRITTS, M. P. Applications of principal component analysis to horticultural research. HortScience, Alexandria, v. 26, n. 4, p. 334-338, 1991.

IRASTORZA, M. H. Aspectos teóricos e aplicados da descrição varietal do feijão (Phaseolus vulgaris L.). 1983. 141 f. Dissertação (Mestrado) - Universidade Federal de Pelotas, Pelotas.

LOARCE, Y.; GALLEGO, R.; FERRER, E. A comparative analysis of the genetic relationship between rye cultivars using RFLP and RAPD markers. Euphytica, Wageningen, v. 88, p. 107-115, 1996.

MOREIRA, J. A. N.; SANTOS, J. W. dos; OLIVEIRA, S. R. M. Abordagens e metodologias para avaliação de germoplasma. Campina Grande: Embrapa-CNPA, 1994. $115 \mathrm{p}$.

NIE, N. H. SPSS: statistical package for the social sciences. 2. ed. New York: McGraw-Hill Book, 1975. 675 p.

PEREIRA, A. V. Utilização de análise multivariada na caracterização de germoplasma de mandioca (Manihot 
esculenta Crantz). 1989. 180 f. Tese (Doutorado) - Escola Superior de Agricultura Luiz de Queiroz, Piracicaba.

PEREIRA, A. V.; VENCOVSKY, R.; CRUZ, C. D. Selection of botanical and agronomical descriptors for the characterization of cassava (Manihot esculenta Crantz) germoplasm. Revista Brasileira de Genética, Ribeirão Preto, v. 15, n. 1, p. 115-124, 1992.

RAMALHO, M. A. P.; SANTOS, J. B.; ZIMMERMANN, M. J. de O. Genética quantitativa em plantas autógamas: aplicação ao melhoramento do feijoeiro. Goiânia: Ed. da UFG, 1993. 271 p.

RAVA, C. A.; MOLINA, J.; KAUFFMANN, M.; BRIONS, I. Determinación de razas fisiológicas de Colletotrichum lindemuthianum en Nicaragua. Fitopatologia Brasileira, Brasília, v. 18, p. 388-391, 1993.

WARD, L. H. Hierarchical grouping to optimize an objective function. Journal of the American Statistical Association, Washington, v. 58, p. 236-244, 1963. 